\title{
PROPOSING A GENERALIZED DESCRIPTION OF VARIATIONS IN DIFFERENT TYPES OF SYSTEMS BY THE MODEL OF PGE - PRODUCT GENERATION ENGINEERING
}

\author{
A. Albers, S. Rapp ${ }^{凶}$, J. Fahl, T. Hirschter, S. Revfi, M. Schulz, T. Stürmlinger and \\ M. Spadinger \\ Karlsruhe Institute of Technology, Germany \\ $\square$ simon.rapp@kit.edu
}

\begin{abstract}
The model of PGE describes the emergence of new systems based on reference by the activities carryover, embodiment and principle variation - qualitatively different manifestations of a transfer process. We investigate indicators which constitute these different manifestations measurably for different types of systems. We propose generalized variation operators to describe system development with respect to different product elements and system types. We use case studies from automotive, production systems and simulation models.
\end{abstract}

Keywords: design theory, engineering change, systems engineering (SE), product generation engineering (PGE), reference system

\section{Introduction}

Several approaches describe relations between technical systems and already existing systems. The description of these relations is amongst others used as a basis for the estimation of innovation potential or development risks. The different approaches refer to different aspects of systems to describe the relation between new and existing systems. Examples are differentiations based on properties or changes of the physical structure. The contribution at hand uses the model of PGE Product Generation Engineering. This model describes the relation between new and existing systems with three types of variation, currently focusing on the system structure and its embodiment to distinguish the different types of variation in the development of mechatronic systems.

Based on observations from three cases, this contribution proposes an extension of the scope of this model to a) other aspects of systems besides structure and embodiment, namely functions and properties, and b) other types of systems besides mechatronic systems.

\section{State of the art}

\subsection{Systems theory and domains of interdisciplinary systems development}

The aim of product development is to develop functional, producible and marketable products (Ponn and Lindemann, 2011). In the development of mechatronic systems, several domains of knowledge mainly mechanical engineering (e.g. design, technical mechanics, manufacturing or drive technology), 
electrical engineering (e.g. electronics, energy or semiconductor technology) and (industrial) information technology - are involved (VDI, 2004). These domains have their own specialist ontologies, experience and models, ways of thinking, methods and tools that have evolved over decades. In the past, product development was often dominated by a single domain of knowledge (VDI, 2004). Due to the dissolution of boundaries (Lindemann, 2016), however, product development becomes a joint and multidisciplinary or interdisciplinary cooperation task (Anderl et al., 2012). The number of persons and disciplines involved is increasing. The full potential can only be exploited through holistic implementation competence. The boundaries between the individual phases of the product lifecycle become blurred; rather, actors from all disciplines (e.g. production system planning, sales or trade, certification service providers, customer service or recycling) are integrated into development projects at an early stage (Lindemann, 2016). Based on Ropohl's theory of system technology (Ropohl, 1975) and in the course of product development according to Albers, an initially vague system of objectives is transformed into a concrete object system by means of an action system (Albers et al., 2012). The system of objectives contains all relevant objectives for the product to be developed as well as their interactions and boundary conditions. In order to illustrate the iterative character of product development and the central role of the developer, the basic activities of analysis and synthesis between target and object systems are supplemented in the extended ZHO model (Albers et al., 2012).

At the same time, they concretize the action system by introducing the knowledge base and the solution space. The people involved in the development project contribute their usually disciplinespecific domain knowledge to the system. The knowledge base is complemented by object analysis (e.g. investigations of existing products or project documentation). Furthermore, in the course of the iterative sequence of creation and validation steps, objects as well as virtual prototypes are analysed using simulation methods. A synthesis step from the created knowledge base into the system of objectives describes the explicit setting, refining and alteration of targets and boundary conditions. Subsequently, a subjective perception and interpretation as well as the individual limitation of the solution space for the development project takes place in the target analysis. In the following object synthesis, principle and form, properties and central functions are modelled mentally, virtually and physically (Albers et al., 2012). In the sense of engineering, the design definition of the solution includes above all the choice of materials, the manufacturing processes, the definition of dimensions, the investigation of spatial compatibility (Pahl et al., 2007). A product model exists for structuring and linking the solution-open and solution-specific elements of the system of objectives formation, which relates the description level of the product properties to the technical subsystems via the level of the product functions (Albers et al., 2018). Within the confined solution space, the action system develops solutions that are first mentally thought through and then synthesized in the form of explicit models, e.g. sketches, diagrams or prototypes (Albers et al., 2018). There are approaches to interdisciplinary system modelling such as CONSENS (CONceptual design Specification technique for the ENgineering of complex Systems) (Gausemeier et al., 2009) or the RFLP approach (Requirements Functional - Logical - Physical) (Kleiner and Kramer, 2013). In the light of different structures, ways of thinking and terminologies in the domains of knowledge, specialist disciplines must be consistently transformed into the model-based world of development (International Council on Systems Engineering (INCOSE), 2007). CONSENS implements all interdisciplinary aspects that are necessary from an engineering point of view in order to describe the principle solution of a mechatronic system in a semi-formal notation: Requirements, environment, application scenarios, functions, effect structure, form and behaviour. Likewise, the aspects requirements, processes, resources and design of the production system are considered, which describe the principle solution of a production system (Gausemeier et al., 2009). The RFLP approach describes the holistic, systematic support for designing and developing from system analysis to physical development and represents the descending branch of the V-model according to VDI guideline 2206 (Kleiner and Kramer, 2013).

\subsection{Approaches to describing the reuse of knowledge}

There are various approaches that describe the relationship between newly developed systems and preexisting underlying systems. Clark and Henderson (1990) distinguishes four types of innovation, 
based on a distinction between component and architectural knowledge following Marples (1961) and Alexander (1964) and the extent to which these types of knowledge change. These four types of innovation are associated with different levels of development risk and economic success.

In the field of Engineering Change, changes to systems are described, whereby very different scopes of changes, points in time or domains affected by changes are possible (Jarratt et al., 2011). With regard to the effects on the success of a development project, a distinction is made between critical and non-critical changes (Langer et al., 2012).

The model of the PGE - Product Generation Engineering according to Albers describes the activities for the development of a new product generation as a combination of three types of variation: carryover variation, embodiment variation and principle variation (Albers et al., 2015) (CV, EV, PV). With these three types of variation, the subsystems of a new product generation are developed. The basis and starting point are always elements of a reference system. This reference system can include everything from subsystems from predecessor product generations, competitive products and up to artefacts from research. All subsystems together with the associated product documentation, which form the basis for the development of a new product generation, are combined in the reference system (Albers et al., 2019a). Figure 1 illustrates the model of the PGE in simplified form using the first Tesla Roadster as an example.

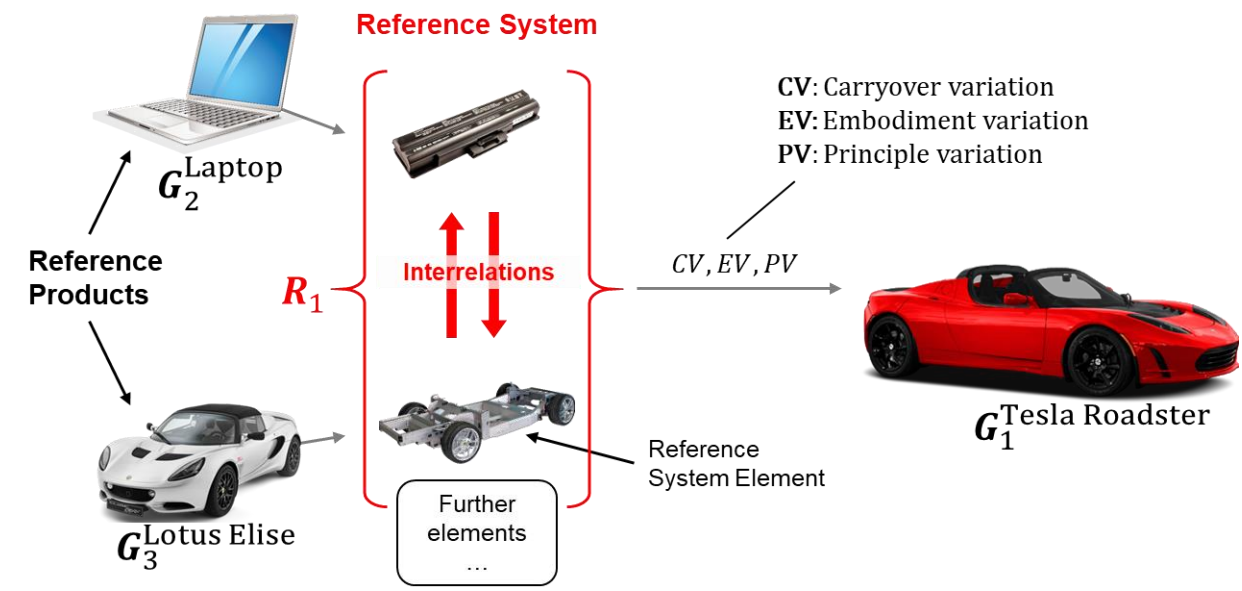

Figure 1. Simplified illustration of the PGE model using the first product generation of the Tesla Roadster as an example, modified based on Albers et al. (2019a)

In the case of the different types of variation, the relationship between embodiment and function is influenced to varying degrees (Albers et al., 2016). This can serve as an indicator to identify the different types of variation in empirical investigations.

In general, all mentioned approaches describe the relation between a new system and existing systems by some form of differentiation. Several aspects of systems, for example, functions, properties or the embodiment, are used as a basis to make this differentiation. The focus of the approaches is on technical systems, but not necessarily exclusively. However, the integration of multiple aspects of a system and consideration of different types of systems is hard to be found.

\section{Research objective and research approach}

The objective of this contribution is proposing an approach for the description of the relation between a new system and already existing systems and different possible forms of this relations, which considers on the one hand different aspects of systems, such as functions, properties or the embodiment, and on the other hand is potentially applicable to different types of systems. This contribution builds up on observed phenomena from different cases of system development.

Ideas from system theory, which gives a basis for a common description of different aspects of systems and different types of systems are used as a basis to propose also a common description of the relation between a new system and already existing systems, based on the observed phenomena. Furthermore, the model of PGE is used as a basis as it already refers to system theory. Different forms of the relation between a new system and already existing systems are depicted by three types of variation. Yet, as 
described in 2.2, indicators for the distinction between these three types of variation focus on the structure and embodiment of mechatronic systems. The contribution is thus based on the following research questions:

- Which observable phenomena beyond changes of the structure and embodiment constitute different forms of variation in the development of a new system based on already existing systems?

- Which observable phenomena constitute different forms of variation in the development of other than mechatronic systems based on already existing systems?

- How can the observed phenomena be integrated into and consistently described based on the three variation types within the model of PGE for different aspects of systems and different types of systems?

The first question is investigated with a case from the automotive industry in section 4.1. For answering the second question, two cases of different systems are investigated in section 4.2 (production system) and section 4.3 (simulation system). With the observation from these three cases, the third question is answered in section 5 by proposing a generalized definition of three types of variations. These definitions build up on the current definitions in the model of PGE, but extend its scope.

All three cases describe the relation between a new system and already existing system in their area. To visualize these relations, elements, their type and attribute as well as linkages in all sections the same symbols depicted in Figure 2 are used.
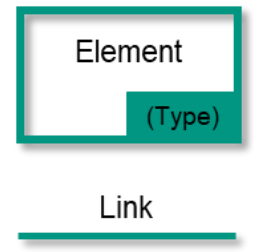
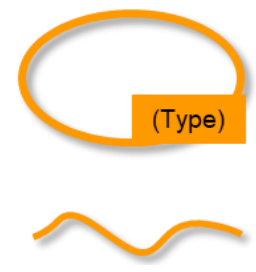

Element with another expression of an attribute (e.g. ,round shape" instead of "rectangular shape")

Link with another expression of an attribute
Removed

element

Removed link

Figure 2. Symbols for the visualization of elements, linkages and changes of their expression in the cases in section 4.1-4.3

At the beginning of each section from $4.1-4.3$ is a description of elements, attributes and linkages for the system investigated in the respective section.

\section{Observations from the cases}

\subsection{Development of a new car product generation}

Mechatronic products can be described at different levels of abstraction via product properties, functions and technical subsystems using a reference product model (Albers et al., 2018). An 18month study at a German automotive Original Equipment Manufacturer (OEM) analysed the propertyfunction-embodiment relationships of a new automotive product generation in relation to its direct predecessor $G_{n-1}$ (Albers et al., 2020). The study showed strong tendencies of connection between the variation of the function-embodiment-relation of subsystems and changes in properties. The product properties and functions are depicted according to the scheme from Figure 2 by the ovals and rectangles at each associated layer as seen in Figure 3. The variation of technical subsystems is illustrated exemplary on the vehicle and marked by the appropriate colour (cf. section 3 ). The relation or linkage of elements on each layer is represented by interconnecting lines, the overarching link of product properties, functions and technical subsystems is depicted by arrows.

Figure 3 illustrates the development of a new vehicle generation $G_{n}$ of an existing product line at a German OEM. The product generation in development is based in particular - but not exclusively - on the predecessor generation $G_{n-1}$, which is reflected in the reference system $\mathrm{R}_{\mathrm{n}}$. From the technical subsystem perspective, elements are varied in the new generation.

In Figure 3, the wheel-tire combination of $G_{n}$ is varied in its embodiment (EV). In addition, a technical principle variation (PV) of the previously fixed spoiler is developed so that it will be movable in $G_{n}$. 
The movable spoiler then leads to a variation of the attributes on a functional level: the downforce of the vehicle can henceforth be actively controlled in the product generation.

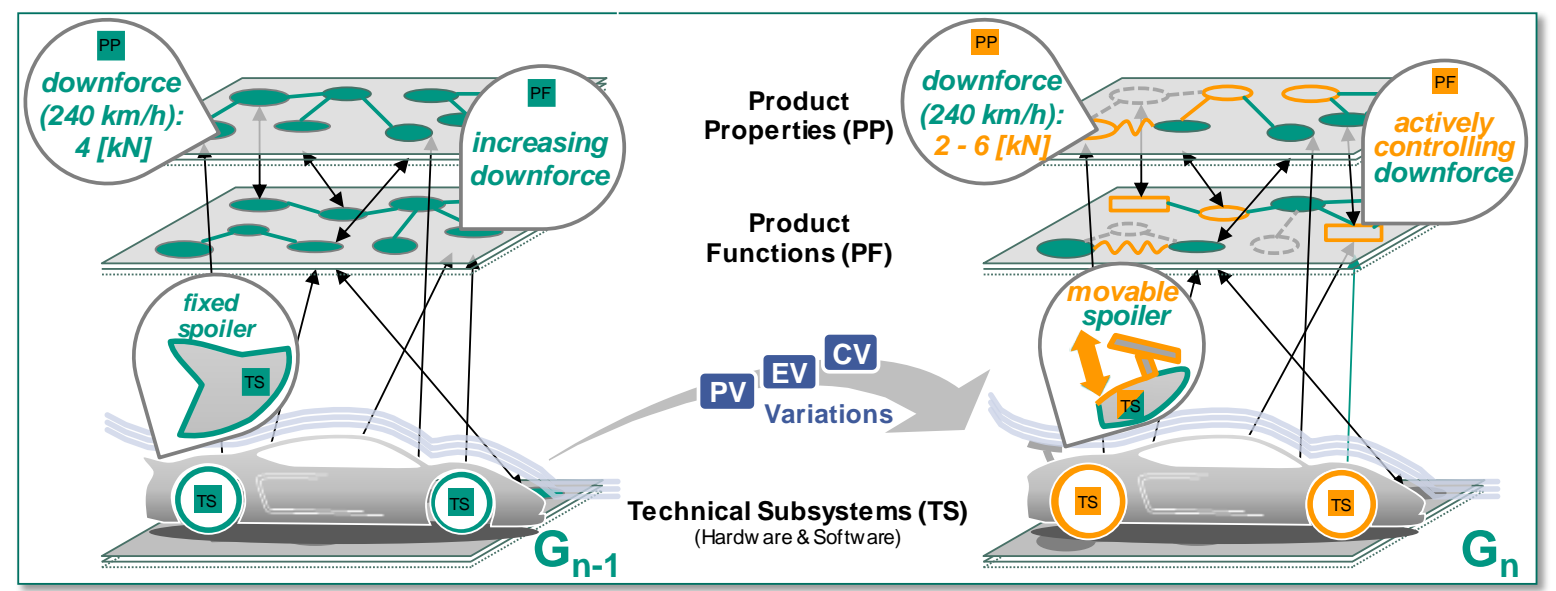

Figure 3. Variation of technical subsystems and their impact on product properties and product functions according to Albers et al. (2018)

From the perspective of the properties, the downforce at $240 \mathrm{~km} / \mathrm{h}$ will change, for example, from a constant $4 \mathrm{kN}$ to a controllable, variable value between $2-6 \mathrm{kN}$. This example demonstrates that the variation of the technical subsystems has a relation to the product functions to be realized and, in the final consequence, its product properties.

In the most extreme type of new development of a product property or function, elements from the reference system are linked and developed new to form a new solution principle. An example of this would be introducing a product property, which describes "flight quality of a vehicle", as well as an associated, fundamentally new product function "landing vehicle", which could be transferred from another context (in this case aviation and aerospace) to the product generation $G_{n}$. In the case of introducing a new product property, the sought-after feature-function and function-design relationship is thus not present in the reference system. In analogy to technical subsystems, product properties (e.g. "acceleration behaviour $0-100 \mathrm{~km} / \mathrm{h}$ " in equal time as in $G_{n-1}$ ) and functions (e.g. "adaptively controlling vehicle speed" analogous to $G_{n-1}$ ) can be transferred from the reference system $\mathrm{R}_{\mathrm{n}}$.

In other cases, it can be observed, that only the attribute of a product property - e.g. reduced "maximum speed of the vehicle" compared to $G_{n-1}$ - or a product function such as "recognizing traffic signs" is extended by additional signs such as time-dependent speed limits from the reference system.

\subsection{Production system development}

The production system is made up of the sum of all production and assembly processes required to manufacture (parts) and assemble a product including the equipment, machines, human resources, information processing and other resources used. According to Eversheim (1989) the production system comprises besides the elements for the technical manufacturing process also organisational elements for planning, development, control and operation of the production processes.

In the development of a production system, variations in one of the systems or processes mentioned usually affect other systems or processes within the production system due to the interactions between them. Albers et al. (2019b) describe an approach for modelling the interactions between product and production system development. The focus here is on two elements of the production system: the production processes and the associated machines. In this section we will therefore discuss in more detail how variations in the product affect the production processes or the machines.

As in the case of a product to be manufactured, the machines for production are also a physical, technical element. The variation types principle variation, embodiment variation and carryover variation within the model of the PGE described in section 2.2 can therefore also be used to describe the development of production machines with focus on the embodiment of those systems as they are also mechatronic systems. The production machines are connected to the product by the production processes. In contrast 
to the machine and the product, these are not physical elements, therefore adaptions of the production processes have to be described differently. In addition, the relationships between the different types of adaption between product, production process and machine are of major importance, as they allow conclusions to be drawn about possible necessary development activities, innovation potential, risks or production planning. On the basis of the following, simple example, adaptions of production processes, more precisely of manufacturing processes, and their linkage to the variations of product and production machine is described. The cube depicted in Figure 4 as example for a product is further developed based on the generation $G_{n-1}$. The product or its design element, the hole, is varied with the parameters shown.

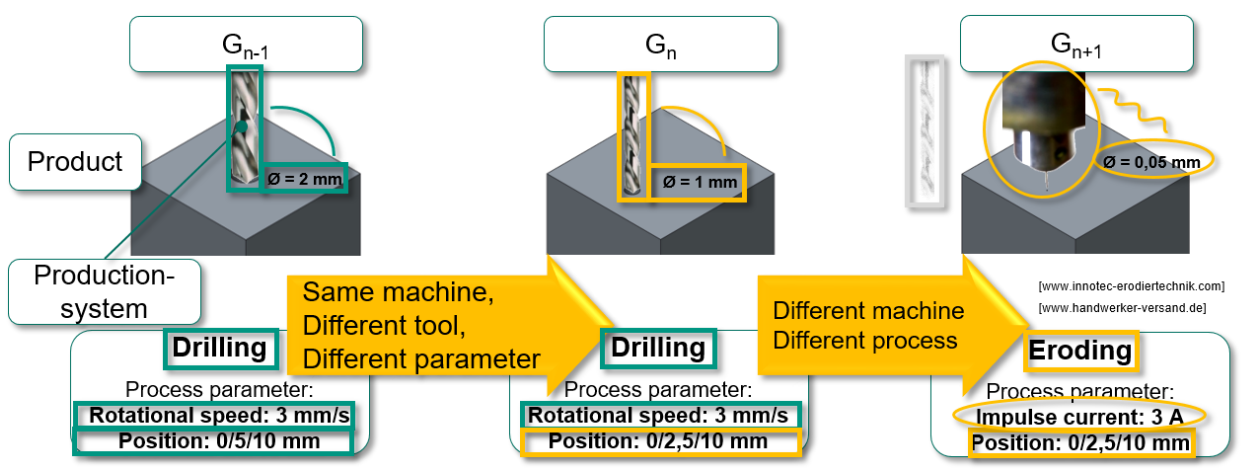

Figure 4. Development of several generations of product and production system with adaptions illustrated using the scheme from Figure 2

The production process and the production machine for making the hole vary accordingly in subsequent product generations $G_{n}$ and $G_{n+1}$ of the production system. Variations in the embodiment of the product or product feature can lead to both parameter changes in already used production processes or new production processes in the production system.

\subsection{Development of simulation models}

By using computer-aided methods, the product developer can be supported in the development of complex products. In order to further increase the significance of the simulation models, different simulation methods must be coupled. A strategic approach for the detailed description of the combination of different simulation methods was presented with the coupling model in Albers et al. (2017). Thereby a distinction is made between environment and virtual system. The environment provides the boundary conditions, which are coupled with the virtual system via interfaces. In order to map the virtual system, various methods, which are understood as individual elements of the system, are interconnected.

Figure 5 shows the current version of a coupling of simulation methods for component temperature calculation and subsequent parameter optimization $\left(G_{n}\right)$ and its predecessor $\left(G_{n-1}\right)$.

The individual models are represented as three-level blocks. The upper field contains information about the method used. The middle field indicates which software is used and the model-specific name is noted in the bottom field. In addition, the arrows define the input and output parameter sets of the methods. When working with the coupled simulation methodology, it is observable that its structure and the requirements placed on it are constantly changing.

In the system shown in Figure 5, an existing parametric optimisation method has been adopted to the temperature calculation process. This optimisation method has been developed in another research project. The existing solution principle could be adopted, only the interfaces had to be adapted accordingly.

In the course of a project it may happen that existing software environments have to be replaced for functional or licensing reasons. For example, the "Fluent" software could replace the "Star-CCM+" flow solver previously used. The input parameter set would remain the same, the simulation method would be different. However, it would be based on a known solution principle.

In the current generation of the simulation methodology $G_{n}$, the temperature calculation of the vehicle components is performed with the calculation tool "Star-CCM+". In order to do this, the simulation method required an input parameter set $\mathrm{P}_{4^{*}}$. The output parameter set $\mathrm{P}_{6^{*}}$ is then analysed by the product 
developer. This procedure resulted from the previous generation $G_{n-1}$, which was adapted. There the software "RadTherm" was used to determine the temperature. This simulation method required an additional parameter set $\mathrm{P}_{5}$ as an input, which was introduced via an interface. This is shown schematically in Figure 5. By changing the simulation method, the input parameter set also changes.

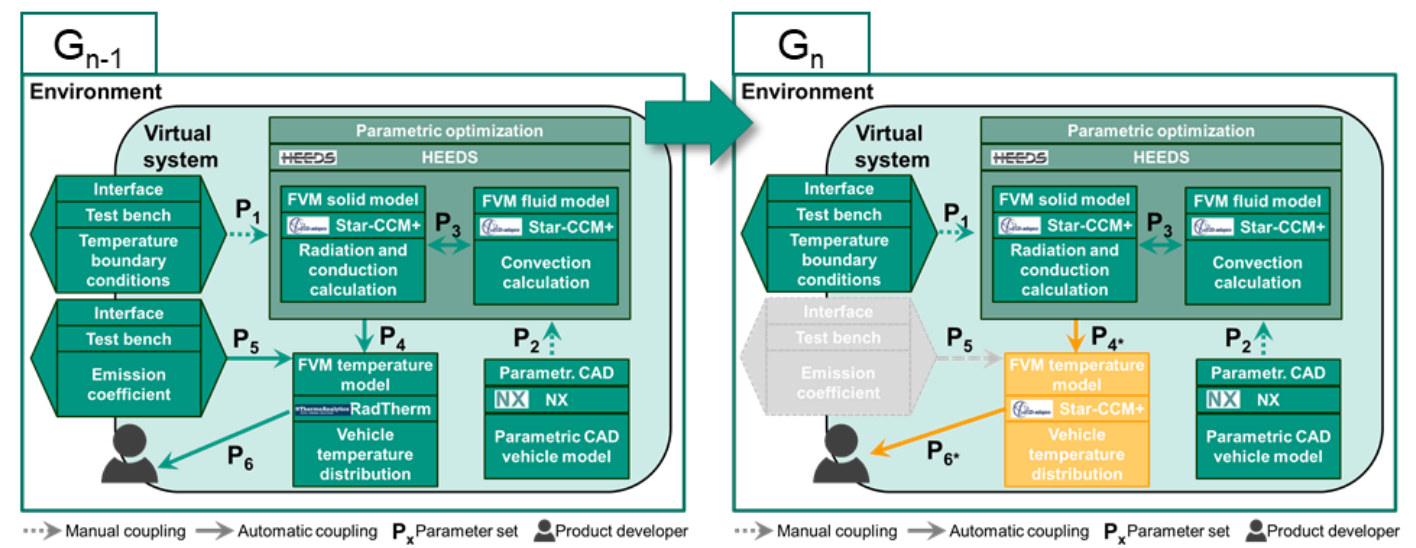

Figure 5. System of coupled simulation models for the calculation of component temperatures; current version $\left(G_{n}\right)$ and its predecessor $\left(G_{n-1}\right)$; Adaptions from $G_{n-1}$ towards $G_{n}$ are visualized using the scheme from Figure 2

\section{Proposing the variation operators in the model of PGE}

The automotive case shows that product properties and functions are transferred from the reference system $\mathrm{R}_{\mathrm{n}}$ to the new product Generation $G_{n}$ by an activity to the carryover variation $(\mathrm{CV})$ of the PGE model which is currently defined with focus on the embodiment of the systems. Furthermore, the adaption of attributes of product properties or functions from the reference system can be observed as well as adding or removing functions or product properties. This is done by activities similar to the current definition of embodiment and principle variation in the model of PGE.

This observation suggests to increase the scope of the current definition of the variations in the PGE model and apply them as well for describing the development of product properties and product functions. However, the term embodiment variation (EV) is very specific to the embodiment of systems (e.g. in the shape of hardware or software components in automotive product development). Therefore, a broader understanding and application of the variations in the PGE model should be reflected in a more general model element. As the "embodiment" variation and similar observed phenomena are about the change in attributes, "attribute variation" is proposed.

The case of the production system development and the development of systems of coupled simulation models also show phenomena, which are similar to the current understanding of the different variation types in the model of PGE and appear equal when described with the system-theory based scheme from Figure 2.

As a conclusion we propose the following generalized definition of three variation types, which is based on the current understanding in the model of PGE but extends the scope of application from the embodiment of mechatronic systems to functions and properties of systems on the one hand and different types of systems on the other hand:

- Carryover variation: an element from the reference system is carried over into the new system generation, whereby the interior of this element is regarded as a "black box" and adjustments are made according to the requirements of system integration and boundary conditions at the interfaces.

- Attribute variation: the link of elements in the reference system is maintained in the new system generation. Thus, the solution principle remains unchanged compared to the reference system. However, the attribute(s) of the elements are varied.

- Principle variation: elements of the reference system and their linkage are varied such that elements and links are removed or added. Thus, a new solution principle is realised, which is new in comparison to the reference system. 
With regard to certain product elements and certain system types, the specific characteristics of the variation types can be described with specific terms. For example, the attribute variation in the case of mechanical elements of mechatronic systems can be referred to as embodiment variation.

With the proposed generalized definitions, the observations from the cases can be classified as follows: Changing the geometrical shape of car components or adapting already existing functions and properties, for example in terms of performance parameters, the change of process parameters with basically the same manufacturing process as well as the domain-specific variation of a simulation software can be described as attribute variation.

The development of the movable spoiler as well as adding a new product function or property in the car case, the change of the manufacturing process in the production system from drilling to eroding and the addition of additional part models and linking sets of parameters in the simulation model are different forms of the principle variation shown in Figure 6.

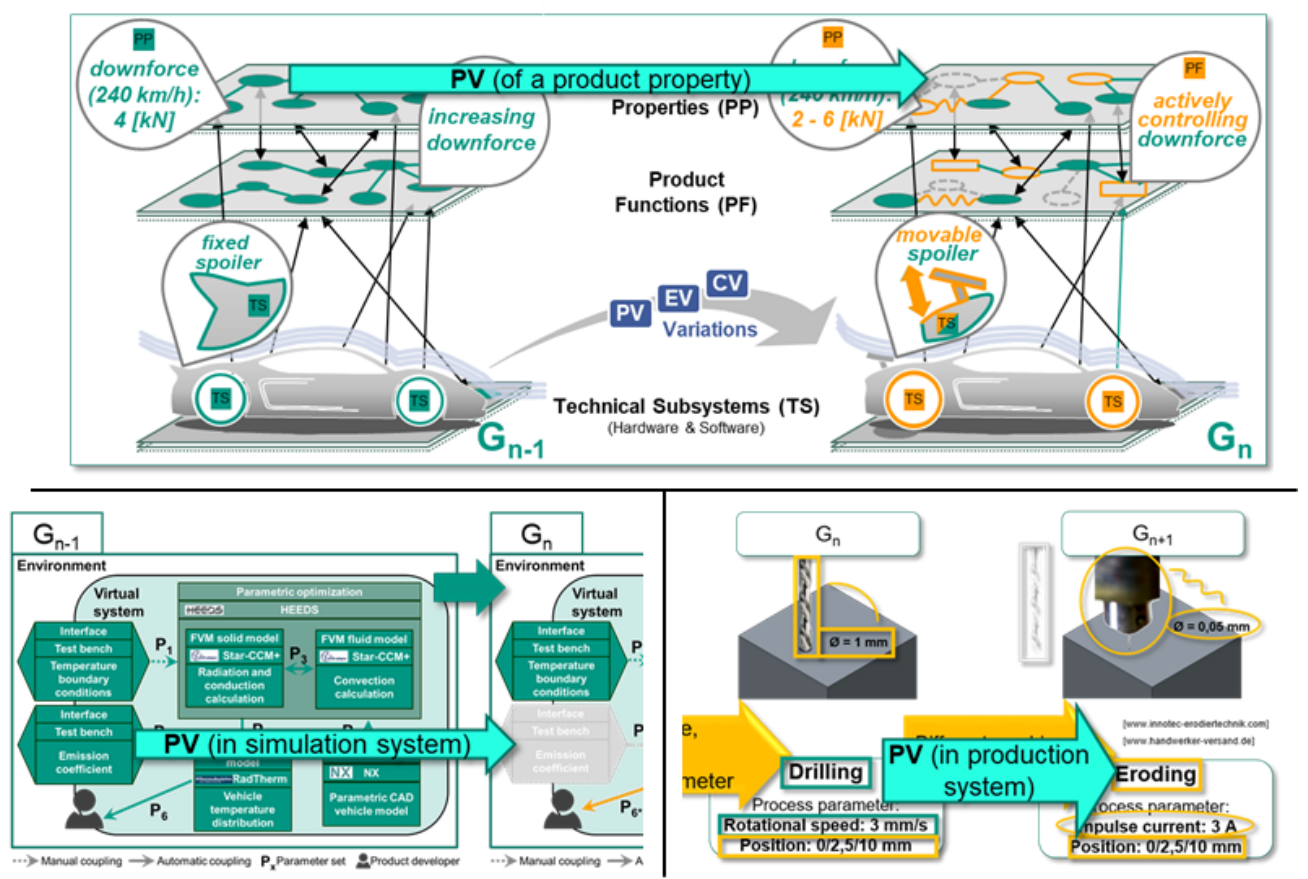

Figure 6. The description of the different cases from section 4.1 to 4.3 with the system-theory based scheme from Figure 2 shows adding or removing of elements and links in all three cases; It is proposed to refer in general to this as "principle variation" (PV)

Where in all three cases subsystems were equally regarded as black boxes during the development of the new system generation and at most interfaces were adapted, carryover variations in different forms can be observed.

\section{Conclusion}

Based on the existing definitions in the model of PGE with three types of variations, which focus on the embodiment of systems, this contribution proposes a more generalized definition of the three types of variation. The three types of variation in the PGE model with the proposed generalized definition summarise observable phenomena in the development in different systems and of different system aspects. The generalized definitions of the variation types have the potential to be applied to other systems, which are not yet investigated from this perspective. However, applying the PGE model with the generalized definitions requires first the definition and modelling of elements and links in the system investigated.

Within the three variation types, additional quantitative characteristics can be expected for further differentiation. An example is the attribute variation of a roller bearing (in this case still called embodiment variation) A reduction of the bearing diameter by $10 \%$ as well as a reduction of the 
diameter by $40 \%$ is an embodiment variation. However, in terms of development risks, among other things, both cases vary quite considerably.

Following the model of PGE, the three types of variation together are sufficient to describe the development of a new system based on a reference system completely. They together can thus be perceived, similarly to mathematical functions, as a variation operator that maps each reference system element in some way on a subsystem of the new system generation, which is developed.

The possibility of being able to describe the emergence and development of different types of systems with the model of PGE suggests to speak here also of a model of SGE - Systems Generation Engineering (Albers et al., 2017a).

\section{Outlook}

The three variation operators in the PGE model and their specific characteristics in the different cases make different observable phenomena measurable. Based on these measures their effects on innovation potential and risks of a development can be examined more closely. On this basis, approaches can be developed for a suitable potential and risk assessment. Figure 7, for example, shows expected risk tendencies in dependence of variations related to properties, functions and the embodiment of technical (sub)systems.

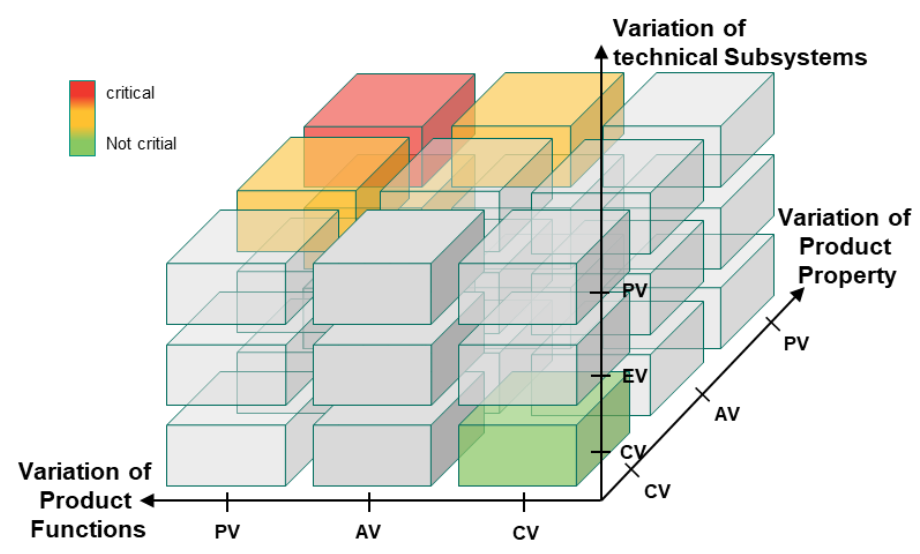

Figure 7. Approach to risk assessment by means of variations with respect to properties, functions and the design of technical (sub)systems

In addition, future work will deal with the characteristics of variation operators for other types of systems that have not yet been recorded. In the investigation of other system types and their development, for example, the development of strategies can also be considered (Arslan et al., 2018).

\section{References}

Albers, A., Bursac, N. and Rapp, S. (Eds.) (2016), "PGE - Product generation engineering Case study of the dual mass flywheel: DS 84", Proceedings of the DESIGN 2016 14th International Design Conference Engineering Design Practice, Cavtat-Dubrovnik, Croatia, 16-19 May 2016. Ed.: D. Marjanović, Vol. 84, The Design Society, Glasgow.

Albers, A., Bursac, N. and Wintergerst, E. (2015), "Produktgenerationsentwicklung - Bedeutung und Herausforderungen aus einer entwicklungsmethodischen Perspektive", Stuttgarter Symposium für Produktentwicklung (SSP) Stuttgart, 19. Juni 2015; Hrsg.: H. Binz, Fraunhofer Verl., Stuttgart.

Albers, A., Ebel, B. and Lohmeyer, Q. (2012), "Systems of objectives in complex product development", in Horváth, I. (Ed.), Tools and methods of competitive engineering: Proceedings of the Ninth International Symposium on Tools and Methods of Competitive Engineering, TMCE 2012, May 7-11, 2012, Karlsruhe, Germany; digital proceedings, Faculty of Industrial Design Engineering Delft University of Technology, Delft, pp. 267-278.

Albers, A. et al. (2017), "Kopplung von CAE-Methoden zur Unterstützung des Produktentwicklers", VDIKonstruktion, Vol. 9, pp. 76-82.

Albers, A. et al. (2020), Model of PGE - Product Generation Engineering by the Example of Autonomous Driving. CIRP Design 2020, Elsevier B.V, Amsterdam, Netherlands, [Submitted Publication]. 
Albers, A. et al. (2018). Supporting Potential Innovation in the Early Phase of PGE - Product Generation Engineering: Structuring the Development of the Initial System of Objectives: R\&D Management Conference, Milano, I, June 30-July 4, 2018.

Albers, A. et al. (2017a), Die Frühe Phase der PGE - Produktgenerationsentwicklung: Stuttgarter Symposium für Produktentwicklung (SSP) Stuttgart, 2017; Eds.: H. Binz, Fraunhofer Verl, Stuttgart.

Albers, A. et al. (2019a), "The Reference System in the Model of PGE: Proposing a Generalized Description of Reference Products and their Interrelations", Proceedings of the Design Society: International Conference on Engineering Design, Vol. 1 No. 1, pp. 1693-1702. https://doi.org/10.1017/dsi.2019.175

Albers, A. et al. (2019b), "Identification of potentials in the context of Design for Industry 4.0 and modelling of interdependencies between product and production processes", Procedia CIRP, Vol. 84, pp. 100-105. https://doi.org/10.1016/j.procir.2019.04.298

Alexander, C. (1964), Notes on the synthesis of form, Harvard Univ. Press, Mass, Cambridge.

Anderl, R. et al. (2012), Smart Engineering: Interdisziplinäre Produktentstehung, acatech DISKUSSION, April 2012, Springer, Berlin, Heidelberg. https://doi.org/10.1007/978-3-642-29372-6

Arslan, M. et al. (2018). "Developing R\&D-Strategies for Future Innovations: Activities in the Context of Technological Transformation and PGE - Product Generation Engineering", R\&D Management Conference, Milano.

Eversheim, W. (1989), Organisation in der Produktionstechnik Band 4: Fertigung und Montage, VDI-Buch, 2nd ed, Springer, Berlin, Heidelberg. https://doi.org/10.1007/978-3-642-61344-9

Gausemeier, J. et al. (2009), Management of cross-domain model consistency during the development of advanced mechatronic systems.

Henderson, R.M. and Clark, K.B. (1990), "Architectural innovation: The reconfiguration of existing", Administrative science quarterly, Vol. 35 No. 1, pp. 9-30.

International Council on Systems Engineering (INCOSE) (2007), Systems Engineering Vision 2020: INCOSETP-2004-004-02, 2.03th ed.

Jarratt, T.A.W. et al. (2011), "Engineering change: an overview and perspective on the literature", Research in Engineering Design, Vol. 22 No. 2, pp. 103-124. https://doi.org/10.1007/s00163-010-0097-y

Kleiner, S. and Kramer, C. (2013), "Model Based Design with Systems Engineering Based on RFLP Using V6", In: Stark, R. and Abramovici, M. (Eds.), Smart product engineering: Proceedings of the 23rd CIRP Design Conference, Bochum, Germany, March 11th-13th, 2013, Lecture Notes in Production Engineering, Springer Berlin Heidelberg, Berlin, pp. 93-102. https://doi.org/10.1007/978-3-642-30817-8_10

Langer, S. et al. (2012), Änderungsmanagement-Report 2012: Studienergebnisse zu Ursachen und Auswirkungen, aktuellen Praktiken, Herausforderungen und Strategien in Deutschland: Änderungsmanagement-Report 2012: Studienergebnisse zu Ursachen und Auswirkungen, aktuellen Praktiken, Herausforderungen und Strategien in Deutschland.

Lindemann, U. (2016), Handbuch Produktentwicklung, Hanser, München. https://doi.org/10.3139/9783446445819

Marples, D.L. (1961), “The Decisions of Engineering Design”, IRE Transactions on Engineering Management, Vol. 8 No. 2, pp. 55-71. https://doi.org/10.1109/IRET-EM.1961.5007593

Pahl, G. et al. (2007), Konstruktionslehre: Grundlagen erfolgreicher Produktentwicklung ; Methoden und Anwendung, Springer-Lehrbuch, 7, Aufl., Springer, Berlin.

Ponn, J. and Lindemann, U. (2011), Konzeptentwicklung und Gestaltung technischer Produkte: Systematisch von Anforderungen zu Konzepten und Gestaltlösungen, VDI-Buch, Springer-Verlag Berlin Heidelberg, Berlin, Heidelberg. https://doi.org/10.1007/978-3-642-20580-4

Ropohl, G. (1975), Systemtechnik: Grundlagen und Anwendung ; mit 5 Tabellen, Hanser, München.

Verein Deutscher Ingenieure, Association of Engineers (2004), VDI-Richtlinie 2206: Design methodology for mechatronic systems, 03.100.40, 31.220.01, 39.020, Beuth Verlag GmbH, Berlin. 